\title{
Development of A Multi-Client Student Attendance Monitoring System
}

\author{
Jia Yi Pang, Kwee Yee Low, Hwee Ling Wong
}

\begin{abstract}
A multi-client student attendance student monitoring system was developed. The attendance system consists of the client and the server. The core functions of the client device are verifying student's identity for attendance recording and monitoring their presence in class. Haar-feature based cascade classifier for object detection and the Scale Invariant Feature Transform Technique (SIFT) technique were implemented for the face authentication process. This paper highlights a full-fledge system architecture with face-based identification implemented on the Raspberry Pi 2 board as the client alongside with RFID authentication for initial identification. The system also has webpage integration for system management. The accuracy achieved was $84 \%$ for face verification and $75 \%$ for face recognition. The experimental result showed that the recognition rate was affected by inconsistency of wearing glasses, distance between the face and the webcam, lighting condition and the environmental background. A database was setup to store attendance and student information. It is supported with a web application to view, update and analyze the attendance data.
\end{abstract}

Index Terms: Attendance system, embedded system, face recognition, web application.

\section{INTRODUCTION}

The student attendance monitoring system was developed to automate attendance recording process and to monitor student attendance in real-time. It was motivated by issues encountered in manual attendance taking system such as fake and unmonitored attendance. The conventional way of taking attendance requires students to sign on an attendance sheet passed around during class. This requires manual update in the system that can be tedious if the student number is high. Otherwise, the instructor may also tick the student attendance manually by calling their names. Likewise, this is only practical for small classes. Recently, QR code-based attendance monitoring was employed whereby a student snaps the QR code displayed by the instructor to record their presence during a given time frame. However, such recording can be done remotely if one receives the QR code.

Revised Manuscript Received on August 18, 2019.

Pang Jia Yi, Faculty of Engineering, Multimedia University, Cyberjaya, Malaysia.

Low Kwee Yee, Faculty of Engineering, Multimedia University, Cyberjaya, Malaysia.

Wong Hwee Ling, Faculty of Engineering, Multimedia University, Cyberjaya, Malaysia
The proposed work can overcome the issues stated above. Face authentication requires biometric signature. Thus, it deters fake attendance as the student must be present to record their attendance. In addition to that, the monitoring feature also $\log$ s the presence of the student in class at predetermined time interval. Identification of late comers and early leavers can be logged so that the instructor can follow up with the students if abnormality is suspected.

Fig. 1 shows the system block diagram. Client devices can be setup in different venues. Since there are many clients, the equipment cost for each client should be minimal and should not interfere with class activities. The clients are connected to a database parked at a server through router using wireless connection. The clients and server can send and retrieve information to/from one another. Radio frequency identification (RFID), face verification and face recognition technology were implemented in the attendance system.

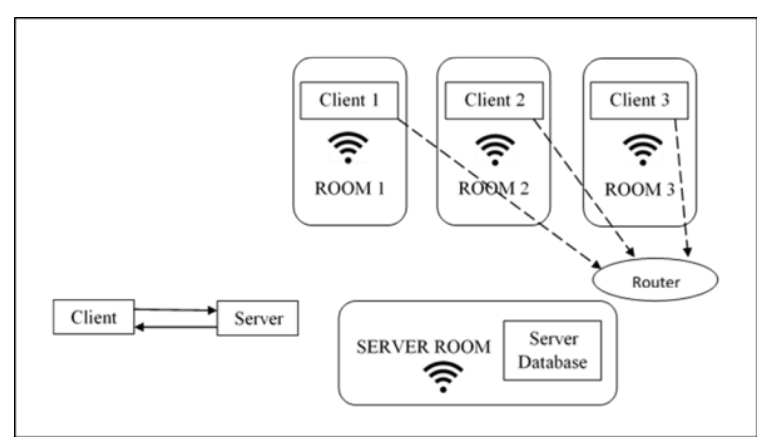

Fig. 1. System block diagram

\section{SIMILAR IMPLEMENTATIONS}

Lim et al. [1] proposed an attendance system using RFID reader and tags. Student name, ID and current date and time were stored in the database. The device stores the attendance taken in its own EEPROM and also the database in a PC. The device sends information to the computer database via serial communication.

Ansari et al. [2] proposed an attendance system based on RFID, biometrics, GSM modem with .Net framework. Student attendance was taken using RFID reader and student ID card. The student identity verification is done using biometric fingerprint scanner. A guardian will be notified about the student's classroom attendance through a message sent using the GSM modem. A website was developed to view the student attendance and present location of a student. A student can also be located by sending roll 
number of the student to the GSM modem.

Ayu and Ahmad [3] proposed the TouchIn System, a webbased attendance system that uses Near Field Communication (NFC) technology. The system consists of a reader unit and a web server. The hardware required is an NFC-enabled mobile device and a computer. The application software is required to be installed on the NFC-enabled mobile devices. By using this system, student information can be read from an NFC-enabled mobile devices or NFC tags. After initial registration, the attendance can be taken by just tapping the device on a smart poster that contains necessary information. Then, a request will be sent to the web server. The drawback of this system is a student must possess an NFC-enable mobile device and internet access.

Kawaguchi et al. [4] proposed an attendance system that takes student attendance using face recognition technology. Continuous observation method is used to improve the face detection rate. The system consists of two cameras. One is used to retrieve a student's seat position. The other camera is used to capture the student's image. Active Student Detect (ASD) is applied to estimate the existence of student sitting on the seat using background subtraction and inter-frame subtraction of the image from the seat sensing camera. The other camera will be directed towards the targeted seat to capture student image for attendance record. Continuous estimation of attendance achieved face detection rate of $80 \%$ and a result of $70 \%$ F-score.

Mao et al. [5] proposed a unified system that can detect faces, track them and recognize them in a video. The "M-versus-N" strategy is used to improve the performance of face recognition while the cascaded Haar-like detector is used for face detection. In face tracking, the face recognizer takes in tracklets as input instead of an image. The workflow of the system starts with a face detection to detect possible faces in a video clip. After that, a multiple object tracking approach is used to recognize the faces detected. The eigen face recognizer used was pre-trained with a huge database of faces under various illumination conditions, poses and expressions. Result showed that the face recognizer achieved an average accuracy rate of $75 \%$ by using the eigen face recognizer and $95 \%$ by using face tracklets.

Joseph and Zacharia [6] proposed a digitized system which consists of a high-resolution digital camera embedded on a micro-controller based motor system to enable the camera to rotate in horizontal direction. In this system, images captured by the camera are sent to a computer and compared with the reference images stored in the database. Feature vectors are generated for input images by using Principal Component Analysis (PCA) and are stored in the database. The eigen value of input images is calculated and compared against the eigen value of the reference images stored in the database. If positive result is obtained, the log table will be updated with the corresponding system time and a face image of the student. Results showed that the proposed face recognition method was sensitive to the background of the face image and head orientation.

Recent development in pattern recognition steers towards implementation of Deep Learning method. Masi et al. [7] conducted a survey on face recognition concentrating on Deep Convolutional Neural Network (DCNN) methods. They summarized the recent face datasets and network architecture. Accuracy of various architectures was highlighted. The accuracy can reach very close to $100 \%$ and the progress was enabled using very deep architecture such as ResNet-101 with the use of large-sized sets. The authors also highlighted that preprocessing steps helped in data augmentation to introduce more variability to the training set. DCNN relies heavily on the training set. Arsenovic et al. [8] developed a DCNN based face recognition as a standalone API to be use with an existing RFID based employee attendance system. The system was employed on a computer platform. They tested on five test subjects and their faces were augmented to generate more training sets. Affined transformation was applied to the test image so that crucial face landmarks were centralized without distorting the image. They achieved an average of $95.02 \%$ of accuracy using a relatively small dataset.

\section{SYSTEM DESIGN}

\section{A. System Components}

The two main parts of the system are the client and the server. The client device is a standalone device. It consists of a single board computer (SBC) to interface with the modules connected to it. The modules and components connected to the Raspberry Pi board in this project includes the MFRC522 RFID module, 16x2 LCD module, Wi-Fi Dongle module, two cameras, LED and buzzer. Fig. 2 shows the block diagram of the client device and Fig. 3 portrays the system layout in a single room setting.

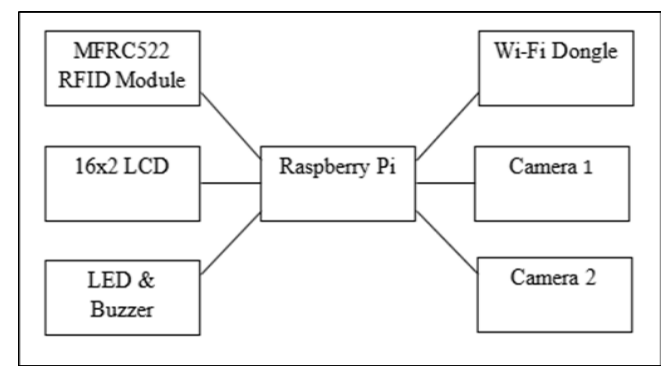

Fig. 2. Client device block diagram

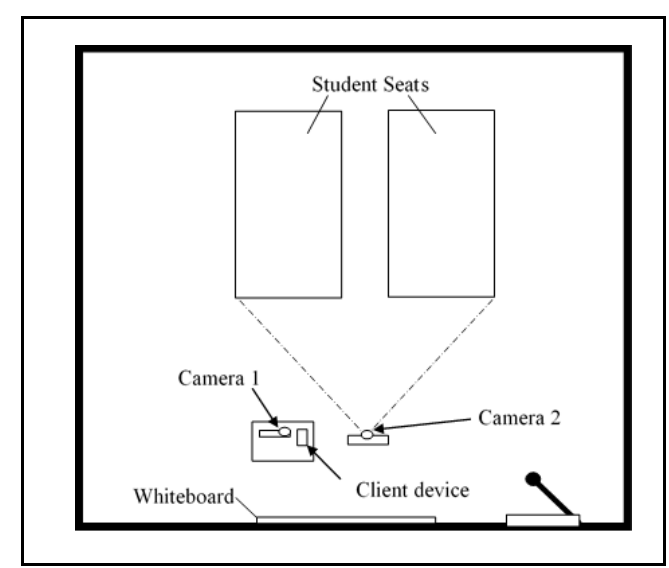

Fig. 3. System setup in a room

MySQL server was employed as the database for the attendance system, as shown in Fig. 4. The database of the system is linked to a webpage which allows administrators 
and instructors to view and edit its information.

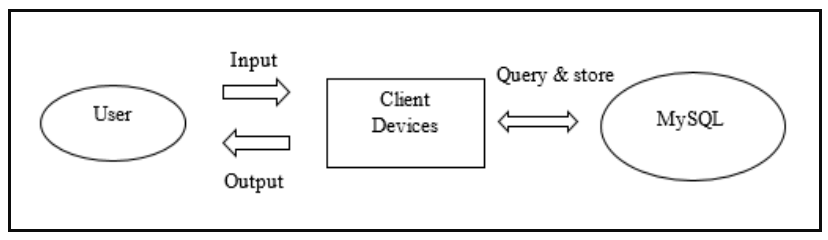

Fig. 4. Web architecture

\section{B. System Operation}

The two main functions of the client device are to verify students' identity for attendance recording and to continuously monitor their presence during class. Attendance taking process begins when a student taps the student ID card on the RFID module. The face verification camera will be switched on to capture a student's image. The image is then processed into image vector and compared with the pre-stored image vector which is matched to the student's profile. Attendance record of the corresponding student is updated to the database if the verification is valid. No changes will be made to the attendance database and the input is aborted if the verification is invalid.

An attendance is updated in the respective subject table according to the assigned timetable. The on-going class is monitored by another camera. Image frames can be captured at a predetermined time interval to check for consistent presence. A missing counter is updated to the attendance database each time a student is found missing.

A webpage was developed for the administrator and instructor. The administrator can access the webpage to key-in new, delete or edit student information. The class timetable can be assigned through the webpage as well. Instructors can view and analyze student attendance rate using the webpage. The attendance will not be counted for student who was found late or missing during class exceeding a certain frequency. The instructor or institution can set the frequency threshold according to their preference.

\section{SYSTEM IMPLEMENTATION}

\section{A. Hardware}

The highlight of this project was implementation of the face verification and monitoring using embedded system with web-integration. The Raspberry Pi 2 Model B was used as the SBC for the client device. The board runs on ARM Cortex A7 at $900 \mathrm{MHz}$ using 1GB SDRAM. Raspberry Pi 2 Model B interfaces with a RFID module via SPI to read the student card. The MIFARE 13.56MHz RC522 RFID Card Reader Module was used. Table I shows the connection of the RFID to the board. The LCD module was used to indicate the status of the face verification process on-site and it was connected to the GPIO pins of the SBC. Two units of 1080p Logitech HD Pro Webcam C920 were used as the cameras
Table I. MFRC522 RFID module connection

\begin{tabular}{|c|l|}
\hline MFRC522 RFID Module & Raspberry Pi 2 Model B \\
\hline $3.3 \mathrm{~V}$ & $3.3 \mathrm{~V}$ \\
\hline RST(Reset) & GPIO 25 \\
\hline GND(Ground) & GND \\
\hline NC & No Connection \\
\hline MISO & GPIO 9 (SPI_MISO) \\
\hline MOSI & GPIO 10 (SPI_MOSI) \\
\hline SCK & GPIO 11 (SPI_SCLK) \\
\hline SDA & GPIO 8 (SPI_CE0) \\
\hline
\end{tabular}

\section{B. Detecting Absentees during Class}

In this project, the face detection technique implemented the Haar feature-based cascade classifier [9] whereas the face recognition technique implemented the Scale Invariant Fourier Transform (SIFT) [10]. The implementations were done using the OpenCV library.

In order to monitor the physical attendance in a class, multiple faces had to be detected. The system can identify early leavers of a class, whereby a person left after attendance was taken or before the class ends. To achieve this objective, the system can find the difference of headcount between frames that were taken in a predetermined time interval.

This system starts by retrieving the timetable for the classroom from the database. If there is a class assigned at that hour, the detection process will be triggered. The image is then processed by the Haar feature-based cascade classifier to detect faces in an image frame. The Viola-Jones's detection method was employed by using AdaBoost learning to select best features. All the faces detected are cropped and stored to a designated folder. The process will repeat after certain time interval but stored at a different location.

The number of face detected is then compared against number of the face detected during the earlier frame. If there is difference in the headcount, the missing face image will be processed and compared against the cropped face image stored in the earlier face verification phase. If the difference of face detected between the frames is above a threshold value, the identity of the missing faces is found using SIFT. SIFT method consists of four steps, namely the scale-space extrema detection, key point localization, orientation assignment and local image descriptor. Matching is done through Euclidean distance. Once the identity of the missing face is recognized, the number of missing frequencies for that student is updated in the database.

\section{Database structure and webpage}

There are two main types of database tables which are the attendance and information tables. Attendance table is used to store student attendance record. On the other hand, information table stores the student information, class timetable and the face image vector. Table II summarizes the types of database table and their functions. 
Table II. Types of database table and their functions

\begin{tabular}{|l|l|l|}
\hline $\begin{array}{l}\text { Types of } \\
\text { database } \\
\text { table }\end{array}$ & Table & Functions \\
\hline Attendance & $\begin{array}{l}\text { Student } \\
\text { attendance }\end{array}$ & $\begin{array}{l}\text { To store attendance taken } \\
\text { daily. }\end{array}$ \\
\hline Information & $\begin{array}{l}\text { Student } \\
\text { informatio } \\
\text { n }\end{array}$ & $\begin{array}{l}\text { To store details about a } \\
\text { student including the } \\
\text { student ID, name and card } \\
\text { UID. }\end{array}$ \\
\cline { 2 - 4 } & Timetable & $\begin{array}{l}\text { To match the subject code to } \\
\text { the time where the class is } \\
\text { conducted. }\end{array}$ \\
\cline { 2 - 3 } & $\begin{array}{l}\text { Student } \\
\text { face image } \\
\text { vector }\end{array}$ & $\begin{array}{l}\text { To match student to their } \\
\text { pre-stored image vectors } \\
\text { and to their information. }\end{array}$ \\
\hline
\end{tabular}

The feature vector of that image was saved into an Extensible Markup Language (XML) file and stored in a folder at the server. The path to that XML file was updated to the MySQL database. The database table is linked to the various web pages as listed in Table III. XAMPP was installed at the server side while MySQL was used to manage the database. NetBeans IDE was used to develop the webpage using the HTML and PHP.

Table III. Linkage between the database and the webpage

\begin{tabular}{|l|l|l|}
\hline $\begin{array}{l}\text { Webpage } \\
\text { name }\end{array}$ & Function & $\begin{array}{l}\text { Relevant } \\
\text { database tables }\end{array}$ \\
\hline Login & $\begin{array}{l}\text { Allow users to login using } \\
\text { username and password. }\end{array}$ & None \\
\hline Home & $\begin{array}{l}\text { Allow instructor to sort and } \\
\text { retrieve attendance. }\end{array}$ & $\begin{array}{l}\text { - Student } \\
\text { attendance } \\
\text { - Timetable }\end{array}$ \\
\hline Student & $\begin{array}{l}\text { Allow admin to view, add, } \\
\text { edit or delete student } \\
\text { information. }\end{array}$ & $\begin{array}{l}\text { - Student } \\
\text { information }\end{array}$ \\
\hline $\begin{array}{l}\text { Timetabl } \\
\text { e }\end{array}$ & $\begin{array}{l}\text { Allow admin to edit the } \\
\text { class timetable. }\end{array}$ & - Timetable \\
\hline Analysis & $\begin{array}{l}\text { Allow lecturer to obtain } \\
\text { student attendance rate. }\end{array}$ & $\begin{array}{c}\text { - Student } \\
\text { attendance }\end{array}$ \\
\hline Logout & $\begin{array}{l}\text { Allow users logout and } \\
\text { return to login page. }\end{array}$ & None \\
\hline
\end{tabular}

\section{RESULTS AND DISCUSSIONS}

\section{A. User Identification on Client's Device}

An experiment had been conducted to test the device stability and to determine the average time taken for a single attendance taking process. The client device was tested repeatedly for 20 times. Face verification was carried out after an ID card was successfully read by the RFID module. The attendance is updated if face verification is valid. The device was able to operate smoothly without failure for all of the trials. The average time taken for a single attendance taking process, which includes face verification, is approximately $6.2 \mathrm{~s}$. The maximum range and direction in reading the RFID module was also observed. Its result is tabulated in Table IV.
Table IV. RFID range of detection and direction

\begin{tabular}{|l|l|l|}
\hline Position & $\begin{array}{l}\text { Direction (towards } \\
\text { RFID reader) }\end{array}$ & $\begin{array}{l}\text { Range of } \\
\text { detection }(\mathbf{c m})\end{array}$ \\
\hline \multirow{2}{*}{ Top } & Parallel & 3.5 \\
\cline { 2 - 3 } & Perpendicular & No detection \\
\hline \multirow{2}{*}{$\begin{array}{l}\text { Side } \\
\text { (Left/Right) }\end{array}$} & Parallel & 0 \\
\cline { 2 - 3 } & Perpendicular & No detection \\
\hline \multirow{2}{*}{ Bottom } & Parallel & 3.5 \\
\cline { 2 - 3 } & Perpendicular & No detection \\
\hline
\end{tabular}

\section{B. Face Verification}

1) Single Face Detection

The experiment was conducted on 200 frontal face images consists of 16 individuals from different skin color, facial expressions and poses [11]. Experimental result using the proposed algorithm showed $100 \%$ face detection rate. Fig. 4 shows examples of the output.
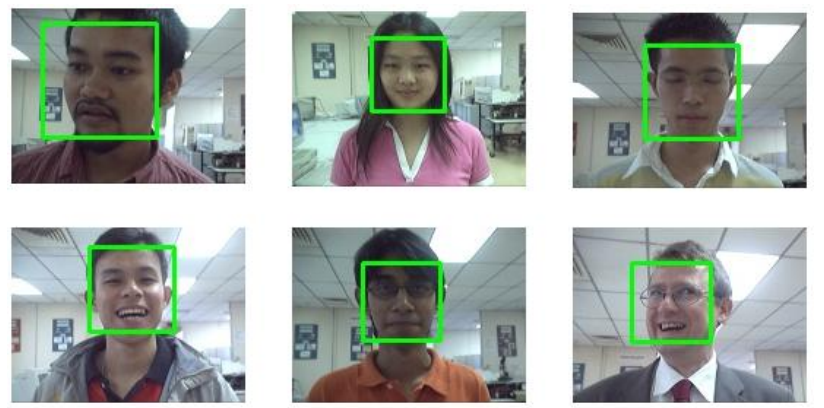

Fig. 4. Samples from the single face detection experiment

2) Face Recognition for Verification

Face verification requires a match with the pre-stored face image of a person. Thus, the feature database had to be prepared beforehand. The feature vector database was prepared by using an image from each individual or student to act as a reference image for the program. The descriptors of images were extracted and stored in the database. The experiment was initially conducted using a laptop with Intel Core i5-2430M (2.40GHz) using Microsoft Visual Studio Community 2015 to measure its accuracy. Only 69 out of 200 images were identified successfully. The average recognition rate is $34.5 \%$. The low recognition rate obtained may be due to greater head pose variations of the test subject as oppose to the training image. If a person is looking away from the camera or the head is tilted severely, the verification rate is affected drastically.

Another experiment was conducted on the SBC at real-time with five reference images (see Fig. 5). The recognition rate gained an average accuracy of is $84 \%$. This is due to the fact that a person tends to look straight at the camera if one knows that his or her face is needed for identification. During the study, it was observed that the distance between the face and the webcam is the main factor that affects the system performance. The recognition rate decreased when the size of the faces got smaller as the student stood further away from the web camera. The average time to detect multiple faces a single image on the laptop is $0.05 \mathrm{~s}$ while the SBC took an average of $3.56 \mathrm{~s}$. This is due to higher processing power of the laptop. 
Nevertheless, the algorithm was successfully applied on Raspberry Pi 2.
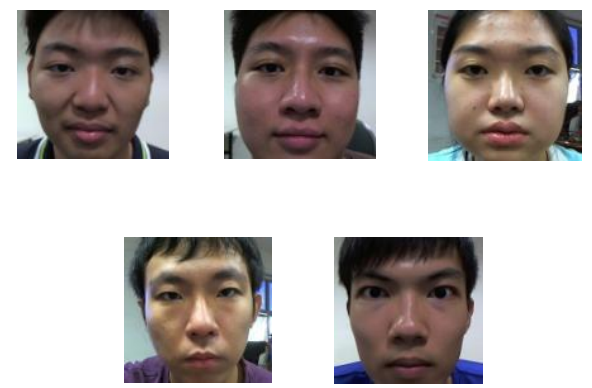

Fig. 5. Subjects for real-time processing

\section{Monitoring of Attendance in a Class}

1) Multiple Face Detection

The experiment was conducted on grouped photos consisting of face images from different gender, skin color and face sizes [12]. The experimental result showed that the multiple face detection accuracy was $86 \%$. The precision of the detection mechanism improved with the size of the face region. Larger face region contributed to higher accuracy. A false positive rate is defined as detecting non-face object as a human face. In this system, the false positive rate was only $5 \%$. Increasing the size of scanning window led to lower false positive rate but also lower detection rate. Fig. 6 shows some outputs of the multiple face detection.
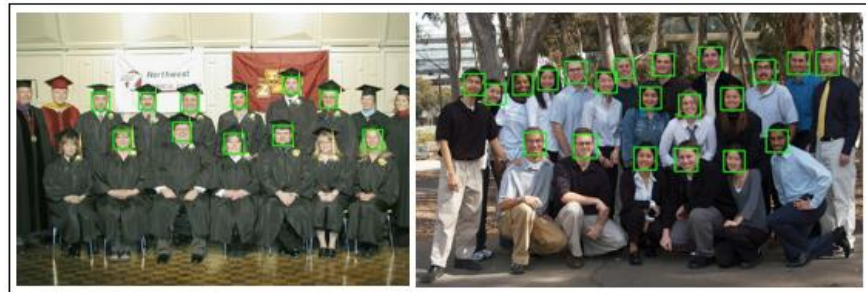

Fig. 6. Samples from the multiple face detection experiment

\section{2) Face Recognition for Identification}

The experiment was conducted on the client device in classroom environment consisting of four students with 160 trials taken in real-time. The recognition rate obtained was $75 \%$. The accuracy of the system is decreased as the students are now sitting further away from the camera. There are a few assumptions to obtain such result. Firstly, the face must face towards the camera while the input image is captured. Secondly, there must not be occlusion on the face region.

\section{CONCLUSIONS AND FUTURE WORK}

A multi-client student attendance monitoring system prototype was developed. The features implemented on the proposed system are RFID card reader, attendance taking and monitoring of the physical attendance by using face detection and verification. The system was fully developed on a Raspberry Pi 2 as the client device and was able to verify the student's identity and identify missing students in the class at real-time. Multiple clients can be setup in each classroom at lower cost using the SBC. The system was also supported by a webpage parked at a server-side for attendance management.
The development of a multi-client student attendance monitoring system can improve the efficiency of attendance taking process. The face verification and class monitoring features provide mechanism to reduce fake attendance in class using contactless biometric identification. However, the accuracy of the face recognition and face detection rate has its limitation. The future work is to employ deep learning techniques on the SBC. Future developments such as mobile application, parental attendance reporting and improvement of webpage graphical user interface (GUI) can be done to enhance the functionality of the attendance system.

\section{REFERENCES}

1. T. S. Lim, S. C. Sim and M. M. Mansor, "RFID based attendance system," IEEE Symposium on Industrial Electronics \& Applications, Kuala Lumpur, 2009, pp. 778-782.

2. Aamir Nizam Ansari, A. Navada, S. Agarwal, S. Patil and B. A Sonkamble, "Automation of attendance system using RFID, biometrics, GSM Modem with .Net framework," International Conference on Multimedia Technology, Hangzhou, 2011, pp. 2976-2979.

3. M. A. Ayu and B. I. Ahmad, "TouchIn: An NFC Supported Attendance System in a Univeristy Environment," International Journal of Information and Education Technology, vol. 4, no. 5, 2014, pp. 448-453.

4. Y. Kawaguchi, T. Shoji, W. Lin, K. Kakusho, and M. Minoh, "Face recognition-based lecture attendance system," Department of Intelligence Science and Technology, Graduate School of Informatics, Kyoto University, 2009.

5. Y. Mao, H. Li and Z. Yin, "Who missed the class? - Unifying multi-face detection, tracking and recognition in videos," IEEE International Conference on Multimedia and Expo (ICME), Chengdu, 2014, pp. 1-6.

6. J. Joseph and K. P. Zacharia, "Automatic Attendance Management System Using Face Recognition," International Journal of Science and Research (IJSR), vol. 2, no. 11, 2013, pp. 327-330.

7. I. Masi, Y. Wu, T. Hassner and P. Natarajan, "Deep Face Recognition: A Survey," 31 st SIBGRAPI Conference on Graphics, Patterns and Images (SIBGRAPI), Parana, 2018, pp. 471-478.

8. M. Arsenovic, S. Sladojevic, A. Anderla and D. Stefanovic, "FaceTime Deep learning based face recognition attendance system," IEEE 15th International Symposium on Intelligent Systems and Informatics (SISY), Subotica, 2017, pp. 53-58.

9. P. Viola and M. J. Jones, "Robust Real-Time Face Detection," International Journal of Computer Vision, vol. 57, no. 2, 2004, pp 127-154.

10. D. G. Lowe, "Distinctive Image Features from Scale-Invariant Keypoints," International Journal of Computer Vision, vol. 60, no. 2, 2004, pp 91-110.

11. H. L. Wong, "Face Detection Using Skin Colour and Eigenface Techniques for Human-Robot Interaction", Faculty of Electrical Engineering, UTM, 2005.

12. "Face Detection Datasets," Face Detection, [Online]. Available: https://facedetection.com/datasets/. 


\section{AUTHORS PROFILE}

J. Y. Pang grew up in Seremban, Malaysia. He graduated from the Multimedia University in the year 2016 with Bachelor of Engineering (Hons.) Electronics. He has three years of industrial experience in the semiconductor $R \& D$ field, mainly on embedded firmware development and machine operation algorithm. He was member of Plexus Manufacturing R\&D software team. Currently, he is a software engineer in Cohu Inc. His expertise is $\mathrm{C}$ and $\mathrm{C}++$ software and firmware developments. His technical interests are programming and machine automation.

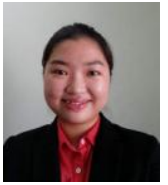

K. Y. Low received the Bachelor of Engineering (Hons.) Electronics majoring in Optical Engineering from Multimedia University in the year 2016. She was a member of SPIE Student Chapter Multimedia University (MMU), Cyberjaya from the year 2014 to 2015 . She has three years of technical experience in the financial technology, focusing on firmware application development for payment terminals. She is currently a software engineer in Soft Space Sdn. Bhd. and her expertise is in C programming. Her technical interests are application development and data analytics.

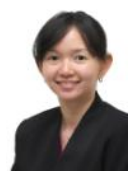

H. L. Wong graduated with B. Eng. degree in Electrical Engineering, majoring in Mechatronics and the M. Eng. degree focusing on robot vision and human-robot interaction from Universiti Teknologi Malaysia in year 2002 and 2005, respectively. She has five years of industrial experience in semiconductor manufacturing, specifically on microcontroller products testing. She joined Multimedia University in 2010 and has been with the university ever since. Her research interests are visual-based automation and mobile robots. 